\title{
Refractory Hepatocellular Carcinoma
}

National Cancer Institute

\section{Source}

National Cancer Institute. Refractory Hepatocellular Carcinoma. NCI Thesaurus. Code C162450.

Hepatocellular carcinoma that is resistant to treatment. 